\title{
Diagnosis and treatment of dementia: 4. Approach to management of mild to moderate dementia
}

\author{
David B. Hogan MD, Peter Bailey MD, Sandra Black MD, Anne Carswell MSc PhD, Howard Chertkow MD, \\ Barry Clarke MD, Carole Cohen BA MD, John D. Fisk PhD, Dorothy Forbes RN PhD, \\ Malcolm Man-Son-Hing MSc MD, Krista Lanctôt PhD, Debra Morgan RN PhD, Lilian Thorpe MD PhD
}

\section{ABSTRACT}

Background: The management of mild to moderate dementia presents complex and evolving challenges. Practising physicians are often uncertain about the appropriate approaches to issues such as the disclosure of the diagnosis, driving and caregiver support. In this article, we provide practical guidance on management based on recommendations from the Third Canadian Consensus Conference on the Diagnosis and Treatment of Dementia.

Methods: We developed evidence-based guidelines using systematic literature searches, with specific criteria for the selection and quality assessment of articles, and a clear and transparent decision-making process. We selected articles published from January 1996 to December 2005 that dealt with the management of mild to moderate stages of Alzheimer disease and other forms of dementia. Recommendations based on the literature review were drafted and voted on. Consensus required $80 \%$ or more agreement by participants. Subsequent to the conference, we searched for additional articles published from January 2006 to April 2008 using the same major keywords and secondary search terms. We graded the strength of evidence using the criteria of the Canadian Task Force on Preventive Health Care.

Results: We identified 1615 articles, of which 954 were selected for further study. From a synthesis of the evidence in these studies, we made 48 recommendations for the management of mild to moderate dementia (28) and dementia with a cerebrovascular component (8) as well as recommendations for addressing ethical issues (e.g., disclosure of the diagnosis) (12). The updated literature review did not change these recommendations. In brief, patients and their families should be informed of the diagnosis. Although the specifics of managing comorbid conditions might require modification, standards of care and treatment targets would not change because of a mild dementia. The use of medications with anticholinergic effects should be minimized. There should be proactive planning for driving cessation, since this will be required at some point in the course of progressive dementia. The patient's ability to drive should be determined primarily on the basis of his or her functional abilities. An important aspect of care is supporting the patient's primary caregiver.
Interpretation: Much has been learned about the care of patients with mild to moderate dementia and the support of their primary caregivers. There is a pressing need for the development, and dissemination, of collaborative systems of care.

Une version française de ce résumé est disponible à l'adresse www.cmaj.ca/cgi/content/full/179/8/787/DC1

CMAJ 2008;179(8):787-93

\section{The case}

You are a family physician caring for Mrs. I, a 72-year-old woman who lives independently with her husband. Mr. I, who is also your patient, calls to tell you that he has become very concerned about his wife's memory. He says that she has reluctantly agreed to come in for an assessment. When seen, she denies any problems with cognition

From the Departments of Medicine and Clinical Neurosciences (Hogan), University of Calgary, Calgary, Alta.; the Division of Neurology, Department of Medicine (Bailey), the Department of Family Medicine (Clarke) and the Department of Psychiatry (Fisk), Dalhousie University, Halifax, NS; the Department of Medicine (Black), Sunnybrook Health Sciences Centre and University of Toronto, Toronto, Ont.; the School of Occupational Therapy (Carswell) and the School of Nursing (Forbes), Faculty of Health Sciences, University of Western Ontario, London, Ont.; the Bloomfield Centre for Research in Aging, Lady Davis Institute for Medical Research, and the Division of Geriatric Medicine, Department of Medicine (Chertkow), Sir Mortimer B. Davis-Jewish General Hospital, McGill University, Montréal, Que.; the Department of Neurology and Neurosurgery (Chertkow), McGill University; and Centre de recherche, Institut Universitaire de Gériatrie de Montréal and Université de Montréal (Chertkow), Montréal, Que.; the Departments of Psychiatry (Cohen, Lanctôt) and Pharmacology (Lanctôt), University of Toronto, Toronto, Ont.; the Department of Medicine (Man-Son-Hing), University of Ottawa, Ottawa, Ont.; and the Institute of Agricultural Rural and Environmental Health (Morgan) and the Department of Psychiatry (Thorpe), University of Saskatchewan, Saskatoon, Sask.

This series is based on recommendations from the Third Canadian Consensus Conference on the Diagnosis and Treatment of Dementia.

Series editor: Howard Chertkow MD, Department of Neurology and Neurosurgery, McGill University, and the Bloomfield Centre for Research in Aging, Lady Davis Institute for Medical Research, Sir Mortimer B. Davis-Jewish General Hospital, Montréal, Que. 
and considers her memory lapses to be normal for her age. Her husband disagrees and itemizes frequent lapses of her recent memory, word-finding problems and difficulties in following complex directions. These problems began about 2 years ago and have progressed gradually since then. Mr. I also says that his wife has gotten lost twice while driving but adds that she has had no car crashes, driving infractions or close calls. Over the last 6 months Mrs. I has needed more assistance balancing her bank accounts and managing the household finances, tasks that she managed without problems over the previous 40 years of their married life. She requires no assistance for her personal care and still does all the household chores, including cooking. She has become anxious whenever left alone and has grown emotionally dependent on her husband. He does not believe she is depressed.

Five years ago Mrs. I had had an episode of transient confusion and amnesia that cleared over 4 hours. She and her husband had gone to a local emergency department and were told it was a possible transient ischemic attack. She has a 10-year history of diabetes mellitus managed by diet and oral metformin therapy. Her regular medications are metformin, enteric-coated acetylsalicylic acid, oxybutynin for urinary frequency and amitriptyline for insomnia.

Mrs. I scores 24 out of 30 on the Mini-Mental State Examination and has problems spacing the numbers on a clock-drawing test. She scores 2 out of 15 on the Geriatric Depression Scale. Findings on physical examination are unremarkable, with no focal neurologic findings. Her blood pressure is normal ( $124 / 76 \mathrm{~mm} \mathrm{Hg}$ while sitting). Laboratory and radiologic investigations are arranged. No reversible cause of dementia is found. Her fasting plasma glucose level is $6.3 \mathrm{mmol} / \mathrm{L}$ and hemoglobin $A_{1 c} 6.8 \%$. Computed tomography scans of her head show minimal whitematter changes and no large-vessel or lacunar infarcts; a carotid Doppler study indicates no significant stenosis.

You diagnose mild Alzheimer disease and are planning to disclose the diagnosis and establish a management plan with Mr. and Mrs. I. How will you proceed and what will you do over the coming weeks and months?

$\mathrm{W}$

ith the growing elderly population in Canada, family physicians will be encountering more patients with Alzheimer disease. The bulk of their medical care will fall to these family physicians, but many of them feel inadequately prepared to diagnose and treat dementia. ${ }^{1}$ Furthermore, in a busy family practice, finding the time and energy necessary to care for older patients with dementia will be an ongoing challenge. Family physicians, and specialists, must be given the tools to manage these patients expertly and humanely.

In this article, we outline an approach for the management of patients like the one described in the case scenario. The approach is based on recommendations made at the Third Canadian Consensus Conference on the Diagnosis and Treatment of Dementia. A description of the process used to generate the recommendations is provided in the first article of the series ${ }^{2}$ and in an online appendix accompanying this article (avail- able at www.cmaj.ca/cgi/content/full/179/8/787/DC2). The case scenario that we have provided highlights a range of the issues that frequently emerge during the management of a patient with dementia due to Alzheimer disease at this stage..$^{3-6}$ Because we cannot cover all 48 recommendations from the consensus conference dealing with this topic, we have focused on those that were selected by the family physicians who participated in the consensus conference as being particularly relevant for primary medical care (for a listing of all 48 recommendations see Appendix 2, available at www.cmaj.ca /cgi/content/full/179/8/787/DC2).

\section{Approach to management}

The diagnosis of dementia is based on the history from the patient, collateral history from an informant and a physical examination. ${ }^{7}$ In the case scenario, Mrs. I's history is straightforward except for the mention of a transient neurologic attack (sudden neurologic symptoms that completely resolve within 24 hours with no clear evidence of migraine, epilepsy, Menière disease, hyperventilation, cardiac syncope, hypoglycemia or orthostatic hypotension) ${ }^{8}$ Mrs. I had nonfocal symptoms of confusion and amnesia. A diagnosis of a transient ischemic attack requires focal symptoms. Patients who experience nonfocal transient neurologic attacks are at increased risk of dementia in the future. ${ }^{8}$ Mrs. I's laboratory results and neuroimaging studies were unremarkable. A diagnosis of Alzheimer disease was made. Although she does have a vascular risk factor (diabetes) and a suspect diagnosis of a transient ischemic attack, there is nothing else to indicate a vascular dementia. An integrative approach to the diagnosis of vascular dementia based on all of the available evidence history, vascular risk factors, findings on physical examination, clinical course, neuroimaging studies and cognitive impairment pattern - is recommended (recommendation no. 4 of the Diagnosis and Differential Diagnosis section in the full set of recommendations, available at www.cccdtd.ca).

Most patients with dementia will be cared for by their family physician (recommendation no. 1, Appendix 2). The management of a patient with Alzheimer disease is a complex task because the condition is progressive and typically evolves over 5-10 years. Family caregivers are important resources, but they have been termed the "hidden patient" because their needs have to be addressed as well. See Box 1 for a list of recommended actions that should be taken by family physicians, or the specialist or dementia service providing the patient's medical care, to assist patients and their families after mild to moderate dementia has been diagnosed. ${ }^{2,910}$ A number of these activities will be ongoing during the course of the illness and will have to be done concurrently with other actions.

For Mrs. I, high-priority management issues at this time would include disclosing the diagnosis, assessing the abilities and needs of her husband as a caregiver, deciding whether a referral is indicated (including a referral to a local office of the Alzheimer Society of Canada), looking for safety concerns (e.g., medication management, driving), addressing advance planning and negotiating a treatment plan with defined goals. Over time, the needs of the patient and her caregiver will evolve. She will 
have to be monitored for increasing cognitive, functional and behavioural challenges as well as her response to the various interventions that might be tried for these problems.

All clinicians caring for patients with mild to moderate dementia have to acquire the core knowledge and skills required to manage a dementia (recommendation no. 27a, Appendix 2 ). A variety of practice issues have been identified by primary care physicians as barriers to the provision of good care. They include insufficient time, inadequate reimbursement, limited access and support from specialists, inadequate coverage of dementia drugs and newer psychotropic agents by publicly funded drug benefit programs, inadequate community resources, poor connections with community agencies, inadequate patient education resources and the lack of interdisciplinary teams. ${ }^{1,11}$ Although some feel that the typical primary care practice cannot deliver the care required by patients with dementia, ${ }^{12}$ a number of innovative collaborative models of care within primary care settings that are designed to provide enhanced integration with community services and improved disease-management support look promising as a way to improve the quality of care and health outcomes of patients with dementia in the community. ${ }^{10,13-15}$ Unfortunately they are not commonly available. Every community should examine the services locally available for the management of patients with dementia, assess their adequacy and implement plans to deal with identified deficiencies (recommendation no. 28a, Appendix 2). Inadequate remuneration should not be a barrier to the delivery of good dementia care (recommendation no. 28d, Appendix 2). Because the medical care of a patient with dementia is multifaceted and time-consuming, physicians may have to consider scheduling several visits over a period of time to deal with its various aspects rather than trying to do too much during a single encounter. As noted in Box 1, interventions such as pharmacotherapy will require periodic reassessments.

The provision of good care to patients with dementia will often require consulting others (recommendation no. 2, Appendix 2). Common reasons for referring a patient to a medical specialist or other health care professional, or to a program or service would include uncertainty about the diagnosis, a request from the patient or family for a second opinion, assistance with pharmacotherapy, assistance with other patient management issues (e.g., depression, behavioural problems, functional impairments), caregiver support, and genetic counselling when indicated. The patient's family physician should be aware of the re- sources available for the care of patients with dementia in their community and, when appropriate, use them. If the attending family physician does not feel able to manage the patient's dementia adequately, he or she should refer the patient to an appropriate specialist service. Internationally there is no agreement on which specialty (e.g., neurology, psychiatry) or subspecialty (e.g., geriatric medicine, geriatric psychiatry) should take the lead in the diagnosis and treatment of Alzheimer disease and other dementias. ${ }^{16}$ Decisions on whom to involve will depend on factors such as the nature of the concern, local availability and preferences of the referring family physician. In a number of cities across Canada, there are multidisciplinary dementia clinics where family physicians and other physicians can obtain help with the care of their patients. These clinics also serve as centres for education and research. ${ }^{17}$

In the case of Mrs. I, there appears to be no need to refer her to a consultant or a dementia clinic unless there was uncertainty about the diagnosis, a request for a second opinion, need for assistance with pharmacotherapy, or an interest in research

\section{Box 1: Recommended actions to assist patients with a mild to moderate dementia and their families after a diagnosis has been made ${ }^{3,9,10}$}

- Inform the patient and his or her family (if present and appropriate) of the diagnosis (this would include general counselling and responding to specific questions)

- Identify the presence of a family caregiver, what support this person can offer, his or her status (i.e., evidence of strain) and his or her needs (this would include trying to deal with any identified needs) - ongoing activity

- Decide on the need for referrals for further diagnostic and management assistance (e.g., referral to genetic clinic for suspected familial cases) ongoing activity

- Assess for safety risks (e.g., driving, financial management, medication management, home safety risks that could arise from cooking or smoking, potentially dangerous behaviours such as wandering) — ongoing activity

- Determine presence of any advance planning documents (e.g., will, enduring power of attorney, personal directive). If there are no such documents, advise that they be drafted. Note that this may include assessing the patients capacity to either draft these documents or whether they should be put into effect.

- Assess the patient's decision-making capacity - ongoing activity

- Refer the patient and family to the local office of the Alzheimer Society of Canada (www.alzheimer.ca/english/offices/intro.htm [English] or www.alzheimer.ca/french/offices/intro.htm [français])

- Provide information and advice about nonpharmacologic and pharmacologic treatment options and availability of research studies*

- Develop and implement a treatment plan with defined goals; continually update plan

- Monitor response to any initiated therapy

- Monitor and manage functional problems (e.g., urinary incontinence) as they arise

- Assess and manage behavioural and psychological symptoms of dementia as they arise

- Monitor nutritional status and intervene as needed

- Deal with medical conditions and provide ongoing medical care

- Mobilize community-based and facility-based resources as needed (this includes being knowledgeable about supportive housing and long-term care options and the appropriate timing, and process, for facility placement)

*The next article in the series will provide details about treatment options. 
studies (e.g., trial of an investigational agent) expressed by the patient or family. As Mrs. I's needs change over time, the question of referral may have to be addressed again.

The elements of management selected for more intensive discussion in this article are disclosure of the diagnosis and decision-making; management of comorbid conditions and medications; assessment of the patient's ability to drive; and support of caregivers.

\section{Disclosure of the diagnosis and decision-making}

On the basis of the principle of autonomy, the diagnosis of dementia should be disclosed to the patient and his or her family or caregiver. This requires incorporating the individual patient's perspective and informing the patient and family or caregiver in a manner that is consistent with the expressed wishes of the patient (recommendation no. 4 from the section on ethical issues in dementia - disclosure, www.cccdtd.ca). ${ }^{5}$ Disclosure can lead to an open dialogue between the patient, his or her family or caregiver, and health care providers about a number of important issues such advance planning, the option of pharmacotherapy and research participation. Although the potential for an adverse psychological reaction is often used as justification not to disclose the diagnosis, a recent study found that this was not the case for most patients and caregivers. ${ }^{18}$ In fact, among distressed patients and caregivers, anxiety often decreased after being told the diagnosis. The question is not "if" the diagnosis of dementia should be disclosed but rather "how" and "when" to do so. ${ }^{5}$

Disclosure has been identified by primary care physicians as a particularly difficult aspect of dementia care. ${ }^{19}$ Unfortunately there is little research on how disclosure of a dementia diagnosis is actually managed in clinical practice. One recent study found that physicians were less than candid with their patients during disclosure and only spent between 40 seconds and 5 minutes and 40 seconds communicating diagnostic information. ${ }^{20}$

Although detailed practical information on how to best disclose the diagnosis is lacking, some general advice can be given. Our suggested approach is similar to what has been recommended for informing patients with cancer of their diagnosis, with certain modifications. ${ }^{21}$ Unique challenges to disclosing a diagnosis of dementia include the lack of insight and impaired cognitive abilities of the patient and the delivery of bad news to several people at once (i.e., the patient and family members) who are unequally prepared for it. ${ }^{22}$ On the other hand, compared with cancer and other life-threatening conditions, there is less time pressure to quickly convey the required information. An individualized approach should be taken that is both sensitive to the patient's unique circumstances and involves the family.

Recommended best practices for the disclosure of a diagnosis of dementia are made up of the following 8 components: ${ }^{23}$

- Prepare for the disclosure: Plan for the meeting; arrange for post-diagnosis support; prepare the patient; elicit the patient's preferences for disclosure.

- Integrate family members: Identify and involve appropriate family members; manage the differing information needs of patient and family; avoid collusion with family members.
- Explore the patient's perspective: Explore the patient's perceptions about his or her symptoms and thoughts about what the diagnosis might be.

- Disclose the diagnosis: Tailor information to the patient's preferences and ability to cope with the diagnosis; check the patient's understanding frequently; explicitly name the illness; acknowledge any diagnostic uncertainty; clarify the relation between dementia and Alzheimer disease; explain the difference between normal aging and dementia; discuss the prognosis.

- Respond to the patient's reactions: Explore the patient's emotional response; elicit and address the patient's questions and concerns.

- Focus on quality of life and well-being: Foster realistic hope; explore coping strategies.

- Plan for the future: Clarify follow-up plans; discuss available support services; negotiate a management plan.

- Communicate effectively: Develop rapport; use appropriate verbal and nonverbal communication; use active listening skills; involve the patient.

The second and third components, and part of the first, start as soon as dementia is suspected (recommendation no. 1 from the section on ethical issues in dementia - disclosure, www.cccdtd.ca). Disclosure is a process, not a one-time meeting. Family members are identified, and time is spent on eliciting the preferences of the patient for disclosure and determining what the patient and family feel might be taking place. Building on this, the actual disclosure (which takes place after the diagnosis has been established), responding to the initial reaction of the patient and family, clarifying short-term follow-up arrangements and negotiating an initial management plan can often be done during a visit lasting 15-30 minutes.

Disclosure, though, should take as much time as is required. With certain patients and their families, 2 or 3 visits over a period of weeks may be required. Information should be given in an empathetic, respectful manner. It can be helpful to give the patient and their family written educational material, especially if it can be customized for the patient. For support and information, patients and their families should be referred to the local office of the Alzheimer Society of Canada (for a listing of local offices, go to www.alzheimer.ca /english/offices/intro.htm [English] or www.alzheimer.ca /french/offices/intro.htm [French]).

Each physician should become acquainted with the laws pertaining to informed consent, the assessment of capacity, identification of a surrogate decision-maker and the responsibilities of physician in these matters. When the diagnosis of dementia is disclosed, it can be an opportune time to suggest that the patient update his or her will and prepare both an advance directive and an enduring power of attorney if the patient has the capacity to complete these documents. Exactly when to broach these topics - whether at the time of the first visit for assessment, when the diagnosis is disclosed or during one of the first few follow-up visits - is not the critical issue. What is paramount is to ensure that these discussions occur before the patient loses the capacity required to declare his or her wishes on these matters. Likewise, a diagnosis of dementia in itself does not mean that the patient lacks capacity to 
make treatment decisions (recommendation \#3 from the section on ethical issues in consent for therapy).

The diagnosis of Alzheimer disease was disclosed to Mrs. I and her family in a manner that was consistent with her expressed wishes. Mrs. I and her family were referred to the local office of the Alzheimer Society of Canada. She and her husband were advised that this would be a good time for her to update her will and prepare both an advance directive and an enduring power of attorney.

\section{Management of comorbid conditions and medications}

The management of comorbid conditions such as diabetes may have to be modified in the presence of dementia (recommendation no. 4, Appendix 2). Comorbidities are often poorly dealt with in the setting of dementia either because clinicians take a nihilistic approach because of the presence of the dementia or they do not modify the care provided in light of the patient's declining ability to self-manage (these responsibilities will typically have to be assumed by a third party such as a family caregiver). This in turn can be a cause of excess disability.

The Canadian Diabetes Association recommends the same glycemic, blood pressure and lipid targets for older as for younger patients unless they have a high level of functional dependency or a limited life expectancy. ${ }^{24-26}$ Patients with a history of symptomatic cerebrovascular disease, such as a transient ischemic attack, should continue therapy to reduce the risk of a recurrent cerebrovascular event and other cardiovascular events. ${ }^{27}$ There is currently no evidence to support the use of acetylsalicylic acid to specifically treat dementia associated with cerebrovascular disease (recommendation no. 4 in the section on dementia with a cerebrovascular component, Appendix 2). Low-dose ASA therapy does not lead to any benefit but significantly increases the risk of a serious bleed in patients with Alzheimer disease with no other potential indication for or definite contraindication to antithrombotic therapy. ${ }^{28}$

Although treatment targets remained the same, the management of Mrs. I's diabetes was modified in light of her dementia. Less reliance was placed on self-management accompanied by an increase in the role her husband was asked to play. Mrs. I was found to currently meet blood pressure ${ }^{25}$ and glycemic targets. ${ }^{26}$ Blood work was requested to assess whether she was meeting her lipid targets. Her current diabetic therapy was continued but with closer supervision by her husband. With Mrs. I's past diagnosis of a suspected transient ischemic attack, her current dose of acetylsalicylic acid was continued since it was considered adequate to reduce the risk of a recurrent cerebrovascular event and other cardiovascular events. ${ }^{27}$

Delirium is common among people with dementia living in the community, with an incidence of $13 \%$ over 3 years in one study. ${ }^{29}$ Caregivers and clinicians should be aware that an abrupt change in the cognition, functional abilities or behaviour of a patient with dementia could represent a delirium. If delirium is confirmed, a search for the precipitating cause coupled with treatment of it and supportive care should be instituted..$^{30}$ When admitted to hospital, people with dementia are at increased risk of delirium. Dementia is the preexisting condition most strongly associated with the develop- ment of delirium in older patients in hospital. ${ }^{31}$ Interventions to decrease the likelihood of this complication should be initiated; these include the use of orienting communication, therapeutic activities, sleep-enhancement strategies, exercise and mobilization, provision of vision and hearing aids, and proactive measures to prevent or manage dehydration (recommendation no. 4a, Appendix 2).

It should be determined whether a patient with dementia is responsible for the management of his or her medications and whether there are problems such as nonadherence (recommendation no. 5a, Appendix 2). A variety of interventions (e.g., blister packaging, use of a dossette, print reminders, phone reminders, pharmacist outreach, visits from a home care nurse) may improve adherence if there is a problem. However, it may be necessary for a third party such as a family member to take over medication management. Even if a patient is currently managing his or her medications well, with or without the use of an adherence aid, planning should begin for the eventual involvement of a third party. With a progressive dementia such as Alzheimer disease, this will eventually become necessary for nearly all patients.

Drugs with anticholinergic effects can worsen the cognitive status of patients with Alzheimer disease and may blunt the effects of cholinesterase inhibitors. ${ }^{32,33}$ In a recent study involving higher-functioning patients in nursing homes, higher rates of long-term functional decline were associated with concurrent use of cholinesterase inhibitors and bladder anticholinergic drugs (oxybutynin, tolterodine) than with the use of cholinesterase inhibitors alone. ${ }^{34}$ The Anticholinergic Risk Scale lists commonly used medications with moderate to very strong anticholinergic potential, and it has been successfully used to identify older patients at increased risk for anticholinergic adverse effects. ${ }^{35}$ The use of medications on this list should be minimized in patients with Alzheimer disease (recommendation no. 5c, Appendix 2).

It was determined that Mrs. I was responsible for her medications and that she was adherent. Her husband was advised that at some point he would have to assume responsibility for her medication management. Mrs. I was taking oxybutynin and amitriptyline, 2 drugs with very strong anticholinergic side effects. The use of these drugs was reviewed, and nonpharmacologic approaches were suggested to deal with her symptoms (e.g., regular toileting for the urinary frequency, and sleep hygiene and daily walking for the insomnia). If Mrs. I's anticholinergic drugs are discontinued, she should be reassessed in a month, since she may show an improvement. Although the consumption of drugs such as oxybutynin can be associated with declines in cognition detected with the use of sophisticated cognitive tests, it is unlikely that clinicians would detect significant changes on the brief cognitive measures used in clinical practice. ${ }^{36}$ For the detection of a subtle cognitive improvement, Mrs. I's physician would have to depend on the observations of her husband.

\section{Assessing ability to drive}

The patient and his or her family should be counselled that a person with a progressive dementia will have to give up driving at some point (recommendation no. 25a, Appendix 2). No 
brief cognitive test such as the Mini-Mental State Examination or a clock-drawing test can be used as the sole determinant of driving ability (recommendation no. 25b, Appendix 2). ${ }^{37}$ Driving is contraindicated in people who, for cognitive reasons, have an inability to independently perform multiple instrumental activities of daily living or any of the basic activities of daily living (recommendation no. 25c, Appendix 2). This degree of functional impairment describes a moderate or worse stage of dementia. The ability of people with a mild dementia to drive should be evaluated on an individual basis. The fairest method of testing involves a comprehensive off- and on-road driving evaluation (recommendation no. 25e, Appendix 2). This type of assessment is not available in all parts of the country and can cost the individual over \$200. If not available, the clinician must rely on her or his judgment. Compensatory strategies (i.e., retraining or education programs, use of copilots, use of onboard navigation and crash warning systems, restricted licensing) are not appropriate for patients with dementia deemed unsafe to drive (recommendation no. 25, Appendix 2). Additional information is available in the Canadian Medical Association's guide Determining Medical Fitness to Operate Motor Vehicles - CMA Driver's Guide. ${ }^{38}$

Mrs. I and her family were counselled that she would have to give up driving at some point because of the progressive nature of her dementia. From the available information, it did not appear that there was an absolute contraindication to her driving, but the report of her getting lost was of concern. She was approached about giving up driving on a voluntary basis and agreed. If she had wanted to continue driving, her driving abilities would have needed to be assessed. The fairest method of doing this would have been to arrange for a comprehensive off- and on-road driving evaluation. If she was evaluated and deemed safe to drive, reassessment of her ability to drive should take place every 6-12 months, and more frequently if indicated (e.g., concerns raised by the family).

\section{Support of caregivers}

The important role of caregivers in providing dementia care must be acknowledged (recommendation no. 26, Appendix 2). The physician should work with the primary caregiver on an ongoing basis and schedule regular appointments with this person. On a regular basis the patient's physician should ask caregivers about any problems with the patient's behaviour. If any are present and distressing, consideration should be given to referring the patient to a specialized dementia service that can offer treatment and support. Caregivers should also be informed of the local home care program, since it may be able to provide information on available community resources, provide anticipatory guidance, assist with personal care when the need arises and look at the need for respite services. The pharmacotherapy of Alzheimer disease can decrease caregiver burden and the time required of caregivers to support the patient. Providing education, counselling, support and respite to caregivers can benefit both them and the patient. Multicomponent interventions using these modalities can significantly delay the need for institutional care for patients with dementia. ${ }^{39}$ Actively involving caregivers and giving them choice seems to be particularly important attributes of successful support programs. ${ }^{40} \mathrm{~A}$ cost- effectiveness study of such a multicomponent intervention found that caregivers receiving the intervention had one extra hour per day not spent in caregiving, at a cost of \$5 per day. ${ }^{41}$

\section{Knowledge gaps}

In this review we have to acknowledge areas of significant gaps in knowledge. For example, we need more research on cognitive training, cognitive rehabilitation and environmental interventions to determine whether these modalities can improve or maintain cognitive and functional performance in patients with mild to moderate dementia.

Unfortunately, we lack a systematic approach across the country to optimally support family physicians in the care of patients with dementia. Remuneration must not be a barrier to the provision of the care required to deal with the complex needs of these patients. Physicians should work provincially and locally to establish these needed systems of care, linking physicians with community agencies and the Alzheimer Society of Canada, to improve the quality of care provided to patients with dementia and their families.

\section{The case revisited}

Mrs. I's family physician schedules regular appointments about every 6 months with her and her husband, both together and separately. The education and support needs of Mr. I are determined and are dealt with as required. If $\mathrm{Mr}$. I had been under the care of a different family physician, he would have been encouraged to visit his own doctor regularly, inform his doctor about his wife's dementia and keep his family physician informed about how it is affecting him. His health and how well he is coping with the demands being placed on him are important aspects of the care of Mrs. I. Mr. I should be assessed for signs of depression, since its prevalence among caregivers of people with dementia is as high as $30 \%-50 \%{ }^{42}$

\section{Conclusion}

The management of patients with dementia is a complex and evolving task. A comprehensive approach is required that focuses on both the patient and his or her primary caregiver. In the next article in this series, we will deal with pharmacologic and nonpharmacologic approaches to the management of symptoms of mild to moderate dementia.

This article has been peer reviewed.

Competing interests: David Hogan has been a site principal investigator in studies supported by Neurochem and Pfizer Canada within the last 3 years and has given presentations sponsored by Janssen-Ortho Inc., Merck Frosst, Novartis and Pfizer within the last 5 years. Peter Bailey has received support from pharmaceutical firms (as a speaker) and the Consortium of Canadian Centres for Clinical Cognitive Research (as president). Sandra Black has received support from Eisai, Pfizer, Janssen-Ortho and Novartis (clinical investigation, continuing medical education [CME] lecturer, ad hoc consultant), Lundbeck (ad hoc consultant, CME lecturer), Sanofi-Aventis (trial investigator) and Myriad (trial investigator, ad hoc consultant, CME lecturer). Howard Chertkow has received support from Pfizer Canada (advisory board member, speaker, grant recipient), Neurochem Inc. (advisory board member), Lundbeck Canada (advisory board member, speaker), Janssen-Ortho Inc. (speaker, 
advisory board member), and Novartis Canada (advisory board member, speaker). John Fisk has received honoraria for lecturing and workshop participation and for providing outcomes research consultation services from AstraZeneca, Bayer, Biogen-Idec, Bristol-Myers Squibb, Novartis, SanofiAventis and TEVA Neuroscience. Krista Lanctôt has received support from Pfizer Canada (consultant, speaker, research support), Abbott Laboratories (consultant, research support), Janssen-Ortho Inc. (consultant, research support) and Lundbeck Canada (research support). Lilian Thorpe has received support for research, for being an advisory board member or for presentations from AstraZeneca, Bristol-Myers Squibb, Eli Lilly, Glaxo SmithKline, Janssen-Ortho Inc., Lundbeck, Novartis, Organon, Pfizer and Wyeth.

Contributors: All of the authors took part in the systematic review for the topic area covered in this article and the creation of the recommendations that were accepted by the participants of the Third Canadian Consensus Conference on the Diagnosis and Treatment of Dementia. David Hogan was the lead author of the article. Peter Bailey, Sandra Black, Anne Carswell, Howard Chertkow, Barry Clarke, Carole Cohen, John Fisk, Dorothy Forbes, Malcolm Man-Son-Hing, Krista Lanctôt, Debra Morgan and Lilian Thorpe provided critical revisions to the drafts of the paper. All of the authors approved the final version for publication.

Editor's Note: The background papers with supporting evidence for the recommendations from the Third Canadian Consensus Conference on the Diagnosis and Treatment of Dementia were published in the October 2007 issue of Alzheimer and Dementia and are available at www.alzheimersanddementia .org. These articles are also freely available at www.cccdtd.ca (through agreement with Elsevier).

\section{REFERENCES}

1. Allen M, Ferrier S, Sargeant J, et al. Alzheimer disease and other dementias: an organizational approach to identifying and addressing practices and learning needs of family physicians. Educ Gerontol 2005;31:521-39.

2. Chertkow H. Diagnosis and treatment of dementia: Introduction. Introducing a series based on the Third Canadian Consensus Conference on the Diagnosis and Treatment of Dementia. CMAJ 2008;178:316-21.

3. Hogan DB, Bailey P, Carswell A, et al. Management of mild to moderate Alzheimer disease and dementia. Alzheimers Dement 2007;3:355-84.

4. Bocti C, Black S, Frank C. Management of dementia with a cerebrovascular component. Alzheimers Dement 2007:3:398-403.

5. Fisk JD, Beattie LB, Donnelly M, et al. Disclosure of the diagnosis of dementia. Alzheimers Dement 2007;3:404-10.

6. Fisk JD, Beattie BL, Donnelly M. Ethical considerations for decision-making for treatment and research participation. Alzheimers Dement 2007;3:411-7.

7. Feldman HH, Jacova C, Robillard A, et al. Diagnosis and treatment of dementia: 2. Diagnosis. CMAJ 2008;178:825-36.

8. Bos MJ, van Rijn JE, Witteman CM, et al. Incidence and Prognosis of Transient Neurological Attacks. JAMA 2007;298:2877-85.

9. Connolly DM, Pedlar D, MacKnight C, et al. Guidelines for stage-based supports in Alzheimer care: the FAST-ACT. J Gerontol Nurs 2000;26:34-45.

10. Cherry DL, Vickrey BG, Schwankovsky L, et al. Interventions to improve quality of care: the Kaiser Permanente-Alzheimer Association Dementia Care Project. Am J Manag Care 2004;10:553-60.

11. Hinton L, Franz CE, Reddy G, et al. Practice constraints, behavioural problems, and dementia care: primary care physicians' perspectives. J Gen Intern Med 2007; 22:1487-92.

12. Boustani M, Sachs G, Callahan CM. Can primary care meet the biopsychosocial needs of older adults with dementia? J Gen Intern Med 2007;22:1625-7.

13. Callahan CM, Boustani MA, Unverzagt FW, et al. Effectiveness of collaborative care for older adults with Alzheimer disease in primary care. JAMA 2006;295: 2148-57.

14. Vickrey BG, Mittman BS, Connor KI, et al. The effect of a disease management intervention on quality and outcomes of dementia care. Ann Intern Med 2006;145:713-26.

15. Bass DM, Clark PA, Looman WJ, et al. The Cleveland Alzheimer Managed Care Demonstration: outcomes after 12 months of implementation. Gerontologist 2003; 43:73-85.

16. Report by the Comptroller and Auditor General. Improving services and support for people with dementia. London (UK): National Audit Office; 2007. p. 27.

17. Jolley D, Benbow SM, Grizzell M. Memory Clinics. Postgrad Med J 2006;82:199206.

18. Carpenter BD, Xiong C, Porensky EK, et al. Reaction to a dementia diagnosis in individuals with Alzheimer disease and mild cognitive impairment. $J$ Am Geriatr Soc 2008;56:405-12.

19. Turner S, Iliffe S, Downs M, et al. General practitioners' knowledge, confidence and attitudes in the diagnosis and management of dementia. Age Ageing 2004; 33:461-7.

20. Karnieli-Miller O, Werner P, Aharon-Peretz J, et al. Dilemmas in the (un)veiling of the diagnosis of Alzheimer disease: Walking an ethical and professional tight rope. Patient Educ Couns 2007;67:307-14.
21. Baile WF, Buckman R, Lenzi R, et al. SPIKES - a six-step protocol for delivering bad news: application to the patient with cancer. Oncologist 2000;5:302-11.

22. Foster NL. Barriers to Treatment: The unique challenges for physicians providing dementia care. J Geriatr Psychiatry Neurol 2001;14:188-98.

23. Lecouturier J, Bamford C, Hughes JC, et al. Appropriate disclosure of a diagnosis of dementia: identifying the key behaviours of "best practice." BMC Health Serv Res 2008;8:95.

24. Meneilly G, Tessier D. Diabetes in the elderly. Can J Diabetes 2003;27(Suppl 2):S106-9.

25. Leiter LA, Mahon J, Ooi TC, et al. Macrovascular complications, dyslipidemia and hypertension. Can J Diabetes 2003;27(Suppl 2):S58-65.

26. Booth GL. Targets for glycemic control. Can J Diabetes 2003;27(Suppl 2):S18-20.

27. Sacco RL, Adams R, Albers G, et al. Guidelines for prevention of stroke in patients with ischemic stroke or transient ischemic attack. Stroke 2006;37:577-617.

28. AD2000 Collaborative Group. Aspirin in Alzheimer disease (AD2000): a randomized open-label trial. Lancet Neurol 2008;7:41-9.

29. Fick DM, Kolanowski AM, Waller JL, et al. Delirium superimposed on dementia in a community-dwelling managed care population: a 3-year retrospective study of occurrence, costs and utilization. J Gerontol A Biol Sci Med Sci 2005;60:748-53.

30. Hogan DB, Gage L, Bruto V, et al. National Guidelines for Seniors' Mental Health - The assessment and Treatment of Delirium. Toronto (ON): Canadian Coalition for Seniors' Mental Health; 2006.

31. Elie M, Cole MG, Primeau FJ, et al. Delirium risk factors in elderly hospitalized patients. J Gen Intern Med 1998;13:204-12.

32. Chew ML, Mulsant BH, Pollock BG. Serum anticholinergic activity and cognition in patients with moderate-to-severe dementia. Am J Geriatr Psychiatry 2005; 13:535-8.

33. Lu CJ, Tune LE. Chronic exposure to anticholinergic medications adversely af fects the course of Alzheimer disease. Am J Geriatr Psychiatry 2003;11:458-61.

34. Sink KM, Thomas J III, Xu H, et al. Dual use of bladder anticholinergics and cholinesterase inhibitors: long-term functional and cognitive outcomes. J Am Geriatr Soc 2008;56:847-53.

35. Rudolph JL, Salow MJ, Angelini MC, et al. The anticholinergic risk scale and anticholinergic adverse effects in older persons. Arch Intern Med 2008;168:508-13.

36. Katz IR, Sands LP, Bilker W, et al. Identification of medications that cause cognitive impairment in older people: the case of oxybutynin chloride. J Am Geriatr Soc 1998;46:8-13.

37. Molnar FJ, Patel A, Marshall SC, et al. Clinical utility of office-based cognitive predictors of fitness to drive in persons with dementia: a systematic review. $J$ Am Geriatr Soc 2006;54:1809-24.

38. Canadian Medical Association. Determining medical fitness to operate motor vehicles - CMA driver's guide. 7th ed. Ottawa (ON): The Association; 2006.

39. Pinquart M, Sörensen S. Helping caregivers of persons with dementia: Which interventions work and how large are their effects? Int Psychogeriatr 2006;18:577-95.

40. Spijker A, Vernooij M, Vasse E, et al. Effectiveness of nonpharmacological interventions in delaying the institutionalization of patients with dementia: a metaanalysis. J Am Geriatr Soc 2008;56:1116-28.

41. Nichols LO, Chang C, Lummus A, et al. The cost-effectiveness of a behavior intervention with caregivers of patients with Alzheimer disease. J Am Geriatr Soc 2008;56:413-20.

42. Saad K, Hartman J, Ballard C, et al. Coping by the carers of dementia suffers. Age Ageing 1995;24:495-8.

Correspondence to: Dr. David B. Hogan, Department of Clinical Neurosciences, Health Sciences Centre, University of Calgary, 3330 Hospital Dr. NW, Calgary AB T2N 4N1; fax 403 283-6151; dhogan@ucalgary.ca

\section{Articles to date in this series}

- Chertkow H. Diagnosis and treatment of dementia: Introduction. Introducing a series based on the Third Canadian Consensus Conference on the Diagnosis and Treatment of Dementia. CMAJ 2008;178:316-21.

- Patterson C, Feightner JW, Garcia A, et al. Diagnosis and treatment of dementia: 1. Risk assessment and primary prevention of Alzheimer disease. CMAJ 2008;178:548-56.

- Feldman HH, Jacova C, Robillard A, et al. Diagnosis and treatment of dementia: 2. Diagnosis. CMAJ 2008;178:825-36.

- Chertkow H, Massoud F, Nasreddine Z, et al. Diagnosis and treatment of dementia: 3 . Mild cognitive impairment and cognitive impairment without dementia. CMAJ 2008;178: 1273-85. 